\title{
Membrane-bound IL-12 and IL-23 serve as potent mucosal adjuvants when co-presented on whole inactivated influenza vaccines
}

\author{
Tila Khan ${ }^{1}$, Connie L Heffron ${ }^{1}$, Kevin P High ${ }^{2}$ and Paul C Roberts ${ }^{1 *}$
}

\begin{abstract}
Background: Potent and safe adjuvants are needed to improve the efficacy of parenteral and mucosal vaccines. Cytokines, chemokines and growth factors have all proven to be effective immunomodulatory adjuvants when administered with a variety of antigens. We have previously evaluated the efficacy of membrane-anchored interleukins (IL) such as IL-2 and IL-4 co-presented as Cytokine-bearing Influenza Vaccines (CYT-IVACs) using a mouse model of influenza challenge.

Findings: Here, we describe studies evaluating the parenteral and mucosal adjuvanticity of membrane-bound IL-12 and IL-23 CYT-IVACs in young adult mice. Mucosal immunization using IL-12 and IL-23 bearing whole influenza virus vaccine (WIV) was more effective at eliciting virus-specific nasal IgA and reducing viral lung burden following challenge compared to control WIV vaccinated animals. Both IL-12 and IL-23 bearing WIV elicited the highest anti-viral IgA levels in serum and nasal washes.

Conclusions: This study highlights for the first time the mucosal adjuvant potential of IL-12 and IL-23 CYT-IVAC formulations in eliciting mucosal immune responses and reducing viral lung burden. The co-presentation of immunomodulators in direct context with viral antigen in whole inactivated viral vaccines may provide a means to significantly lower the dose of vaccine required for protection.
\end{abstract}

Keyword: Influenza, Whole inactivated virus vaccine, Adjuvant, Cytokine, IL-12, IL-23

\section{Findings Introduction}

The use of novel adjuvants, non-replicating virus-like particles (VLP), whole inactivated influenza vaccines (WIV), universal vaccines, and others are potential approaches to address current influenza vaccine challenges $[1,2]$. Interestingly, in mice WIV have been shown to be more immunogenic and induce superior mucosal IgA responses when administered intranasally (I.N.) compared to split vaccines [3]. Intranasal administration of WIV can lead to B cell dependent hetero-subtypic immunity that is associated with elevated lung and serum sIgA and IgG levels [4]. The use of novel adjuvants in combination with WIV may serve to modulate and enhance both mucosal and systemic immune responses with the potential benefit

\footnotetext{
*Correspondence: pcroberts@vt.edu

'Department of Biomedical Sciences and Pathobiology, 1981 Kraft Drive, Corporate Research Center, Virginia Tech, Blacksburg, Virginia 24061, USA Full list of author information is available at the end of the article
}

of antigen sparing and costs associated with vaccine production [5]. Cytokines have great potential to serve as potent and specific adjuvants due to their diverse role in immune responses [6,7]. They are actively being evaluated for use as adjuvants for intranasal vaccine formulations [8] and have been used extensively as soluble adjuvants co-administered with numerous vaccines $[9,10]$, or in a fused or linked form directly with antigen $[7,11]$. The superior immunogenicity of WIV as compared to split or subunit influenza vaccines [12,13] encouraged us to utilize WIV bearing cytokines as a more immunogenic vaccine formulation.

Previous studies in our laboratory have evaluated the adjuvant potential of membrane-anchored IL-2, IL-4 and GM-CSF directly incorporated on inactivated influenza virus particles in mice and chickens $[14,15]$. Cytokine bearing Influenza Vaccine (CYT-IVAC) formulations are derived from mammalian cell culture propagation techniques. Here, influenza A virions are harvested from 
infected MDCK cell lines that are constitutively expressing membrane-bound cytokines at their cell surfaces. As the virus buds and is released they recognize and incorporate the membrane-bound cytokine into the virion envelope. In the present study we expanded our panel of immunomodulators to include IL-12 and IL-23 and evaluated their immunogenicity and protective efficacy by different routes of immunization in young adult mice. IL-12 is a Th1 polarizing cytokine that promotes the differentiation of naïve CD4 + T helper cells towards a Th1 phenotype and stimulates both NK cells and T cells to secrete the immunomodulatory cytokine, IFNY $[16,17]$. Co-administration of IL-12 during intranasal vaccination has proven to be efficacious in stimulating enhanced immune responses to pneumococcal [18] and HIV antigens [19] as well as the induction of systemic and mucosal CTL responses [20]. Recently, we demonstrated that both IL-2 and IL-12 can serve as immunopotentiating agents in influenza vaccines tailored for the elderly [21]. Here, we expanded upon those observations and evaluated whether IL-12 and IL-23 in a membrane-bound formulation would serve as mucosal adjuvants for influenza WIV in young adult mice.

\section{Methods}

The cDNA encoding for mouse derived immunomodulators IL-12 and IL-23 was fused inframe to the membrane anchoring regions of the hemagglutinin (HA) of $\mathrm{A} / \mathrm{WSN} / 33$ influenza virus as previously described $[15,21]$. The mIL-12 gene derived from pORF-mIL-12 (p35:p40) plasmid (InvivoGen) and the mIL-23 (p19: $\mathrm{p} 40)$ gene construct synthesized in vitro $\left(\right.$ GenScript $\left.{ }^{\circ}\right)$, both encode for a single chain open reading frame in which both subunits are linked by a hydrophobic linker molecule (see Additional file 1: Figure S1). Cytokine gene amplicons were further subcloned into the pcDNA3.1 HA1513 vector using restriction endonuclease sites HindIII and BamHI. Madin-Darby canine kidney cells (MDCK) constitutively expressing membrane-bound IL12/HA and IL23/HA were established and surface expression of membrane bound cytokines was validated by indirect immunofluorescence microscopy as described previously [15,21]. Double gradient purified whole inactivated influenza vaccines (WIV) were produced from influenza $\mathrm{A} / \mathrm{PR} / 8 / 34$ (H1N1) virus infected MDCK producer cell lines as described previously and incorporation of membrane-bound cytokines was further validated by western blot analysis of whole viral lysates [15,21]. All animal experiments were performed based on the guidelines of $\mathrm{NIH}$ and approval of Institutional Animal Care and Use Committee (IACUC) of Virginia Polytechnic Institute and State University. 8-10 week old female Balb/c mice (Mus musculus) from Charles River Laboratories (CRL) were allowed to acclimate for at least 10 days prior to onset of vaccination studies. Lightly anesthetized animals (isoflurane inhalant) were immunized either intramuscularly (I.M.) $(0.5 \mu \mathrm{g} /$ $100 \mu \mathrm{l}$ volume of PBS) or intranasally (I.N.) $(3 \mu \mathrm{g} / 10 \mu \mathrm{l}$ volume of $\mathrm{PBS}$ into the nostrils) with inactivated double gradient purified control WIV (A/PR/8/34), CYTIVAC $^{\sim \text { mIL12 }}$ and CYT-IVAC ${ }^{\sim \mathrm{mIL} 23}$ ( $\mathrm{n}=5$ mice/group). PBS administered intramuscularly (I.M.) served as mock ( $\mathrm{n}=5$ mice/group). On day 21, all mice were administered I.M. a booster dose (I.M. group, $100 \mathrm{ng}$ and I.N. group, $500 \mathrm{ng}$ total viral protein) of vaccine. Blood was collected from the retro-orbital sinus on day 19 and day 35 postvaccination. Lightly anesthetized animals were challenged intranasally on day 36 post-vaccination with 100 mouse lethal dose $50\left(\mathrm{MLD}_{50}\right.$ : $50 \mu \mathrm{l}$ volume $)$ of mouse-adapted influenza $\mathrm{A} / \mathrm{PR} / 8 / 34$ virus. Body weights and clinical symptoms were monitored daily. All animals were sacrificed at day 4 post-challenge to determine viral lung loads. Sera, lungs, and nasal washes were collected post-mortem for biological assays. Quantitative levels of influenza-specific total IgG and IgA antibodies in serum or nasal washes were determined by enzyme-linked immunosorbent assay, ELISA [15]. For standard curve generation, anti-mouse IgG (SouthernBiotech) or anti-mouse IgA (SouthernBiotech) antibodies were serially diluted 2 fold from $160 \mathrm{ng} / \mathrm{ml}$ to $0.03125 \mathrm{ng} / \mathrm{ml}$ (IgG) or $512 \mathrm{ng} / \mathrm{ml}$ to $0.03125 \mathrm{ng} / \mathrm{ml}$ (IgA) respectively. Serum samples were diluted 1:20 while nasal washes were undiluted for IgA determination. Quantitation of viral loads in frozen lung samples was determined by tissue culture infectious dose assay [15].

\section{Results and discussion}

Our construct design allows for the expression of murine IL-12(p35p40) and IL-23(p19p40), both heterodimeric cytokines, as single chain full-length IL-12p35p40 and IL-23p19p40 entities joined by a intra-subunit linker segment fused to the 71 amino acid long membrane anchoring region (short stalk, transmembrane and cytoplasmic tail domain) of the HA gene $\left(\mathrm{HA}^{1513}\right)$ derived from influenza A/WSN/33 (H1N1) virus [15] (see Additional file 1: Figure S1). The latter serves to anchor the heterodimeric cytokine within the plasma membrane and is recognized by the virus assembly and budding machinery ensuring packaging within virions. Single chain IL-12 and IL-23 were chosen as they have been shown to be bioactive in vitro and in vivo using this constellation [22,23]. Following stable transfection of the virus permissive MDCK cell line with recombinant plasmids pcDNA3.1-IL-12 (p35p40)/HA ${ }^{1513}$ and pcDNA3.1-IL-23 (p19p40)/HA ${ }^{1513}$ ) the constitutive cell surface expression of the IL-12 and IL-23 cytokine fusion proteins were confirmed by immunofluorescence microscopy using IL12p40 specific antibodies (see Additional file 1: Figure S2). MDCK control cells did not stain positive for surface IL-12 (Additional file 1: Figure S2A) or IL-23 (Additional file 1: 
Figure S2B). To prepare whole virus vaccines, MDCK stable transfectants were infected with influenza virus (A/PR/8/34) and virions bearing membrane-bound IL-12 $\left(\right.$ CYT-IVAC $\left.^{\sim \mathrm{mIL} 12}\right)$ and IL-23 (CYT-IVAC $^{\sim \mathrm{mIL} 23}$ ) were harvested from the supernatants, gradient-purified and subsequently inactivated using $\beta$-propiolactone (BPL) [15]. Non-adjuvanted whole inactivated virus (A/PR/8/34) WIV grown from influenza virus infected wild type MDCK cells was used as control in this study.

Western blot analysis probed with antibodies specific for IL-12 or IL-23 was employed to validate full-length incorporation the heterodimeric cytokine fusion constructs into the specific CYT-IVAC formulations (Figure 1). Separation and staining of the CYT-IVAC ${ }^{\sim \text { mL1212 }}$ and CYT-IVAC $^{\sim \mathrm{mIL} 23}$ formulations respectively (Figure $1 \mathrm{~A}, \mathrm{~B}$ ) revealed a prominent band of approximately $70 \mathrm{kDa}$ in molecular weight. The predicted molecular weights of membrane-bound IL-12 and IL-23 constructs are 68.93 and $66.87 \mathrm{kDa}$ respectively. The cytokine specific bands were not detected in our control non-adjuvanted WIV formulation (PR8). HA incorporation was quantitated using western blot analysis [15] and quantitation of cytokines (IL-12 and IL-23) was performed (Figure 1C) using an IL12/IL23p40 specific bead assay as described by the manufacturer (eBioscience). Together, these data confirm that our CYT-IVAC formulations display fulllength membrane-bound immunomodulators in direct context with full-length viral hemagglutinin and other virion-associated proteins.

To explore in vivo adjuvanticity, female Balb/c mice were immunized with BPL-inactivated control WIV (A/ PR/8/34), CYT-IVAC $\sim$ mIL12 and CYT-IVAC ${ }^{\sim \mathrm{mIL} 23}(\mathrm{n}=5 /$ group) either intramuscularly (I.M.) or intranasally (I.N.). On day 21, all mice were administered a booster dose of vaccine (I.M.). The I.N. prime followed by the I.M. boost was employed to mimic priming of mucosal antibody responses elicited during infection, followed by subsequent stimulation of systemic immune responses that may only be marginally elicited by the mucosal route, yet are actively stimulated following parenteral vaccination. Based on total viral protein administered, animals received $165 \mathrm{ng} / 0.33 \mathrm{ng}$ (I.M.) and $1 \mu \mathrm{g} / 165 \mathrm{ng}$ (I.N.) of HA protein respectively during the prime/boost immunizations.

Anti-viral antibody levels elicited by CYT-IVACs and control non-adjuvanted WIV were determined on both pre-boost (day 19) and post-boost sera (day 35). As anticipated, I.M. immunization induced higher serum antiviral IgG responses as compared to the mucosal (I.N.) route supporting previous reports in both animal [24] and human [25] vaccine studies (Figure 2). Booster vaccination I.M. was given in all vaccine groups (both I.M. group and I.N. group) to boost primary responses and led to significantly higher antiviral IgG levels post-boost ( $40 \mathrm{ng} / \mathrm{ml}$ to $520 \mathrm{ng} / \mathrm{ml}$ ) (Figure $2 \mathrm{~B}$ ) compared to preboost levels ( 25 to $205 \mathrm{ng} / \mathrm{ml}$ ) within the I.M. group (Figure 2A). Interestingly, serum IgG antibodies were detected in the intranasal groups only following parenteral boosting (5 to $650 \mathrm{ng} / \mathrm{ml}$ ). The levels were significantly greater compared to mock (PBS group) ("p $<0.05$ ); albeit there were no significant differences among vaccinated groups (Figure 2C).

Further characterization of the antibody isotypes following booster vaccination revealed significantly higher levels of anti-viral serum IgA in animals that received CYT-IVAC $^{\sim \mathrm{mIL} 12}$ and CYT-IVAC ${ }^{\sim \mathrm{mIL} 23}$ by the I.N. route (Figure 3A) compared to control WIV. Interestingly, I.M. administration of CYT-IVAC ${ }^{\sim \text { mIL12 }}$ also induced significantly higher levels of serum anti-viral IgA. Nasal immunization of soluble cytokines IL-12, IL-1 $\alpha$, IL-18 with an HIV peptide has been shown to induce antiHIV peptide serum and mucosal IgA [19]. This is the first report that membrane-bound IL-12 and IL-23 presented mucosally also stimulate serum anti-viral IgA.

All immunized animals were challenged on day 36 with $100 \mathrm{LD}_{50}$ of mouse-adapted influenza virus $\mathrm{A} / \mathrm{PR} / 8 / 34$ (H1N1) virus and sacrificed four days later for determining
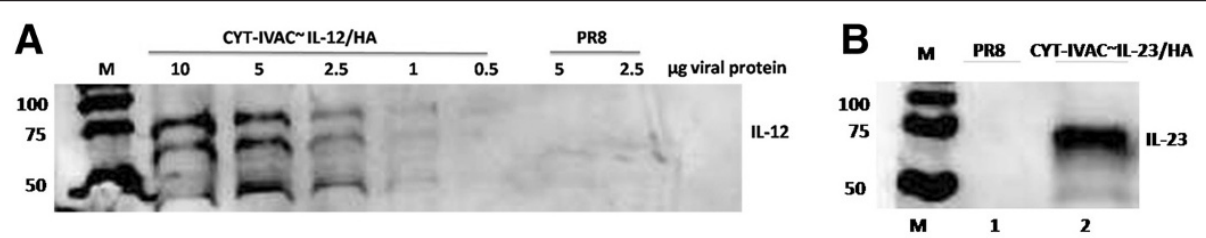

\begin{tabular}{|l|c|}
\hline \multicolumn{1}{|c|}{ Vaccine } & Total Cytokine (pg/ $\mathbf{\mu g}$ of vaccine) \\
\hline WIV (PR/8/34) & N/A \\
\hline CYT-IVAC IL-12/HA & 23 \\
\hline CYT-IVAC IL-23/HA & 156 \\
\hline
\end{tabular}

Figure 1 Western blot analysis of CYT-IVAC ${ }^{\sim 12}$ and CYT-IVAC ${ }^{\sim \text { IL23 }}$. Whole viral lysates were run on 12\% SDS-PAGE gel, blotted on PVDF membrane and incubated with IL-12/23p40 antibody followed by anti-species secondary antibodies conjugated to HRP. (A) Dilutions of CYT-IVAC ${ }^{\sim L-12}$ ranging from $10 \mu \mathrm{g}$ to $0.5 \mu \mathrm{g}$ of protein and (B) CYT-IVAC ${ }^{\sim L-23}$ (lane 2) (5 $\mu \mathrm{g}$ ) and PR8 (lane 1) $(5 \mu \mathrm{g})$ were probed with anti-IL12/23 p40 antibody (eBioscience). (C) Quantitation of virus-incorporated cytokine (pg of cytokine per $\mu \mathrm{g}$ of vaccine) (FlowCytomix ${ }^{\mathrm{TM}}$, eBioscience). 


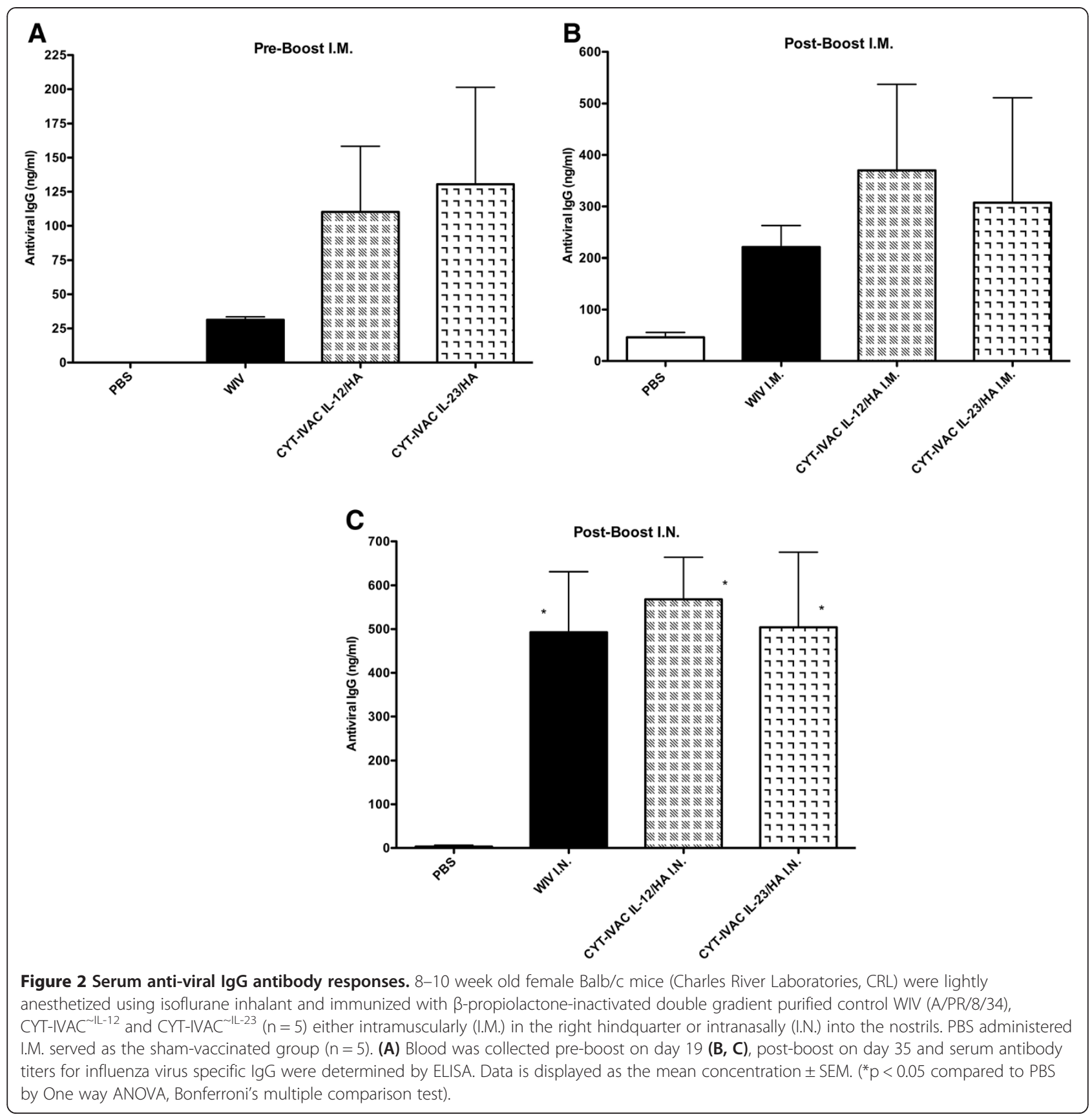

pre-existing vaccine induced protective responses. Since mucosal antibodies present in the respiratory tract are known to provide significant protection from influenza infection [26], we collected nasal washes from animals at day 4 post-infection and determined the anti-viral sIgA levels as a measurement of the vaccine-induced mucosal responses; anti-viral sIgA was not detectable in nasal washes of naïve challenged animals at day 4 (PBS group, Figure $3 B$ ). Both CYT-IVAC ${ }^{\sim \text { mIL23 }}$ and CYT-IVAC $\sim$ mIL12 vaccinated groups exhibited significantly higher levels of influenza-specific sIgA $(\mathrm{p}<0.001)$ compared to the control
WIV group, suggesting that both serve as potent mucosal adjuvants when co-presented in a membrane-bound formulation in direct context with WIV.

Surprisingly, high influenza-specific sIgA levels were also detected in the nasal washes of animals that received CYT-IVAC $^{\sim \mathrm{mIL} 23}$ and CYT-IVAC ${ }^{\sim \mathrm{mIL} 12}$ strictly by the I.M. route (Figure $3 \mathrm{~B}$ ). This is not without precedence, as the transcutaneous or epicutaneous route of immunization coupled with mucosal adjuvants including bacterial toxins, chemical enhancers of cyclic AMP and the active form of Vitamin D3 have been reported to induce peripheral DC 


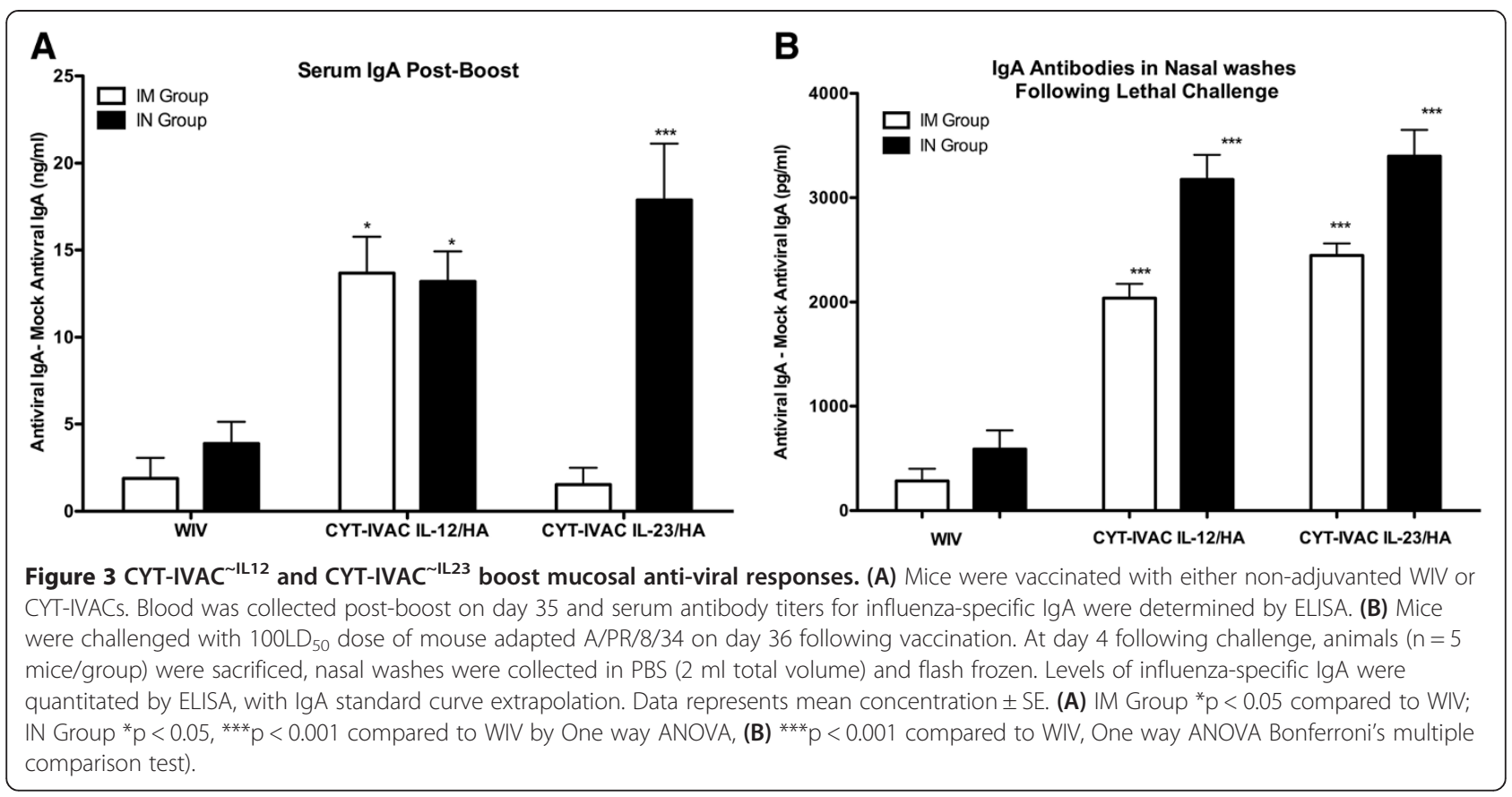

migration to Peyers patches (mucosal tissues) and subsequent priming of $\mathrm{T}$ and $\mathrm{B}$ cells for mucosal homing [27-29]. Hence, our membrane-anchored IL-12 and IL-23 adjuvants may be activating dendritic cells in muscle tissue and targeting them to migration in draining lymph nodes, in a state that is conducive for priming $\mathrm{T}$ and $\mathrm{B}$ cells for homing to mucosal tissues.
A reduction in viral titers in lung tissue of vaccinated animals following viral challenge serves as a valuable correlate of protective efficacy of viral vaccines [30]. Whereas I.M. vaccination of either CYT-IVAC $\sim$ mIL23 or CYT-IVAC $^{\sim \text { mIL12 }}$ was able to reduce viral lung loads at day 4 post-challenge compared to non-vaccinated controls, they only trended towards a better protective
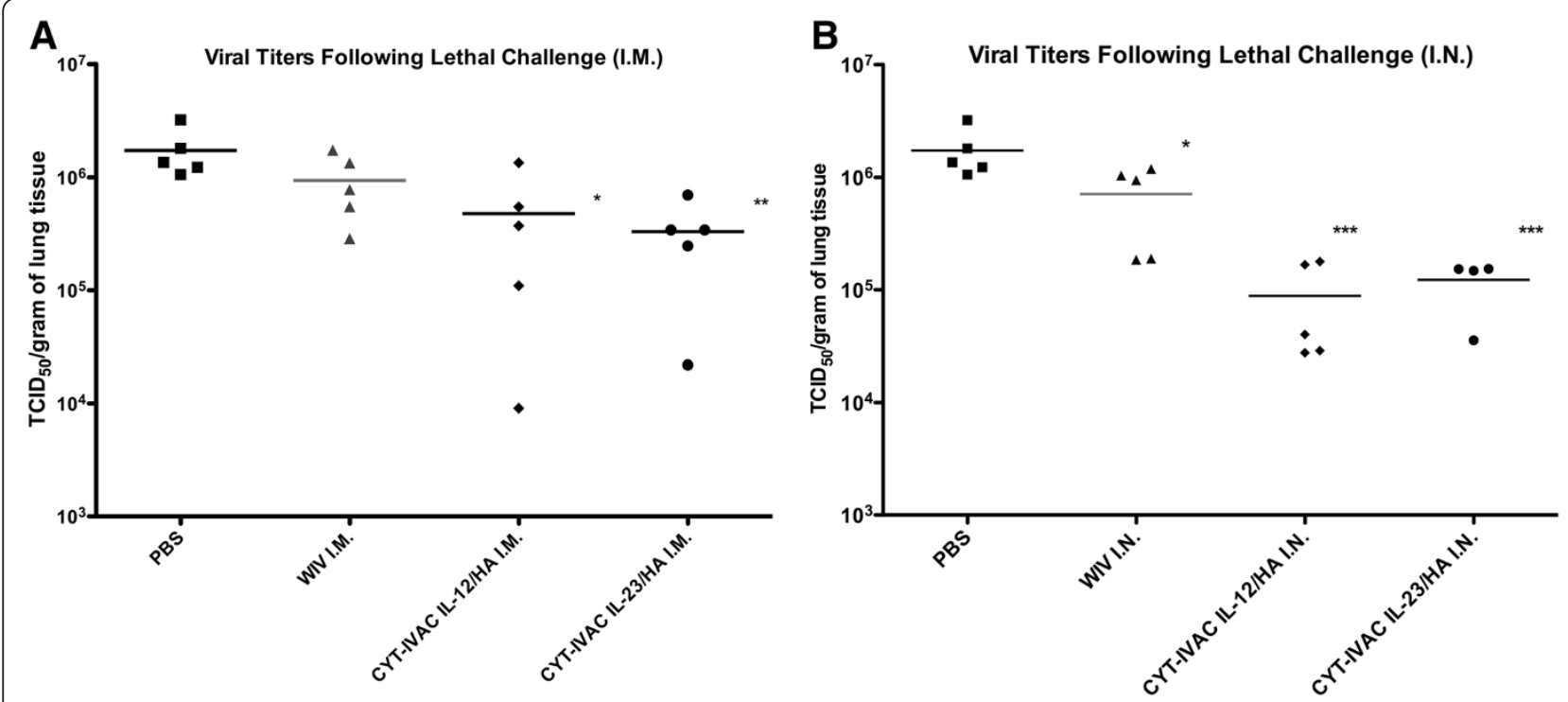

Figure 4 CYT-IVAC immunization reduces viral lung burden following challenge. Animals vaccinated I.M. (A) or I.N. (B) were challenged with a $100 \mathrm{LD}_{50}$ dose of mouse-adapted A/PR/8/34 on day 36 following vaccination. At day 4 following challenge, animals $(n=5)$ were sacrificed, lung tissues were collected and flash frozen. Viral loads from homogenized lung tissue $(n=5)$ were determined by tissue culture infectious dose assay. Data is expressed as $\mathrm{TCID}_{50}$ per gram of lung tissue. ${ }^{*} \mathrm{p}<0.05,{ }^{* *} \mathrm{p}<0.01,{ }^{* * *} \mathrm{p}<0.001$ compared to PBS, one way ANOVA, Bonferroni's multiple comparison test. 
response compared to non-adjuvanted WIV (Figure 4A). Interestingly, we found that recall IgA levels in nasal washes were significantly higher in both CYT-IVAC groups than the WIV non-adjuvanted group following lethal challenge irrespective of the route of administration. These responses may be responsible for some of the variation of viral lung loads observed in animals receiving CYT-IVACs by the IM route. However, this also suggests that there are fundamental differences in the specificity of mucosal induced anti-viral IgA compared to anti-viral IgA responses induced at other parenteral sites.

Mucosal administration of CYT-IVAC ${ }^{\sim \mathrm{mIL} 23}$ or CYTIVAC $^{\sim \text { mIL12 }}$ led to significantly reduced viral loads upon challenge compared to the non-adjuvanted WIV control group (Figure $4 \mathrm{~B}$ ); these data correlated well with the observed high levels of sIgA detected in serum and the nasal wash of these animals. This is the first time that the membrane-bound IL-12 or IL-23 co-presented directly on influenza WIV has been found to induce robust mucosal immune responses. Soluble IL-12 as a nasal adjuvant is well documented [6] and has been reported to stimulate mucosal sIgA and systemic IgG antibody as well as cellular responses in a variety of vaccine formulations [8]. Our data supports these observations, but also suggest that even low concentrations of IL-12 (picograms) can be used in a membrane-bound formulation to boost mucosal sIgA levels. IL-23 inducing mucosal antibody responses is a novel observation and clearly further work is required to address the mechanism. Based on previous reports of IL-17 influencing B cell activation [31] and germinal center development [32], the IL-23 bearing CYT-IVAC could be modulating Th17 responses. Recently, activation of lung Th17 cells were also found to induce the development of polymeric Ig receptor and elevate mucosal secretion of IgA antibodies [33]. Besides IgA antibodies, anti-viral IgG in BAL fluids as well as $\mathrm{T}$ cell responses all contribute towards protection and recovery from viral challenge.

Our approach of using cytokines in direct context with WIV vaccines involves very low amounts of cytokine (picograms per microgram of vaccine). This approach may potentially lower the amount of antigen required to induce protection and may also lower the incidence of adverse side effects reported for WIVs. In most studies soluble cytokines have been administered in $\mu \mathrm{g}$ amounts, which is clearly well in excess of the amounts utilized in the present study; albeit the total number of doses and dosing schedules vary significantly depending on the study (reviewed extensively in $[8,10]$. It should be noted that soluble IL-23 has been reported to have adverse effects such as inducing chronic inflammation and autoimmune disease $[34,35]$ and both antitumor and tumor promoting effects [36,37]. Our approach that limits systemic distribution of cytokines may overcome some of the safety issues and potential autoimmune inflammatory reactions from soluble IL-23.

In summary, this is the first report of the nasal adjuvanticity of both IL-12 and IL-23 in a membrane-bound formulation co-presented with WIV. In light of our recent study using our CYT-IVAC approach in "aged" mice, we hypothesize that both the IL-12 and IL-23 expressing CYT-IVAC formulations may show even more promise as a mucosal formulation for the elderly, but this will require further more in depth investigation. Finally, this study revisits the use of WIV vaccine formulations adjuvanted for mucosal delivery. Future experiments focusing on evaluating protective efficacy of dose sparing with mucosally administered CYT-IVAC ${ }^{\sim \mathrm{IL}-12}$ and CYT-IVAC ${ }^{\sim \mathrm{IL}-23}$ vaccines in both young and old preclinical challenge models are needed to provide greater insights on the efficacy of these vaccines.

\section{Additional file}

\begin{abstract}
Additional file 1: Figure S1. Pictorial diagram of CYT-IVAC gene constructs. (A) CYT-IVAC $C^{\mathrm{LL}-12}$ fusion gene construct (1620 bp) was composed of mlL-12p35p40 subunits joined by short hydrophobic linker molecule(Li) fused in frame to the a short $222 \mathrm{bp}$ coding region of the Hemagglutinin (HA) gene derived from Influenza virus (A/WSN/33), which encodes for a short extracellular stalk region and the transmembrane and cytoplasmic tail region of the HA (HA1513). (B) The CYT-IVAC ${ }^{\mathrm{IL}-23}$ fusion gene construct was constructed in a similar fashion. Both cytokine genes were subcloned into the pcDNA3.1 expression vector, placed under control of the CMV promoter (pCMV). Figure S2. Indirect immunofluorescence cell surface staining of MDCK transfectant cell lines cell lines constitutively expressing mIL-12/HA (C) and mIL-23/HA (D) with MDCK cells serving as negative control $(A, B)$ using cytokine specific antibodies
\end{abstract}

\section{Abbreviations}

CYT-IVAC: Cytokine bearing influenza vaccine; WIV: Whole inactivated virus influenza vaccine; I.M.: Intramuscular; I.N.: Intranasal; IL-12: Interleukin-12; IL-23: Interleukin-23.

\section{Competing interests}

The authors declare that they have no competing interests.

\section{Authors' contributions}

TK was responsible for construct design and assembly, establishing MDCK producer cell lines, vaccine production and characterization, completion of serological assays (ELISA), design and completion of vaccine efficacy studies, overall study design, analysis and interpretation of results, statistical analysis, drafting and reviewing the manuscript. LH participated in animal experimental design and execution. $\mathrm{KPH}$ participated in study design and interpretation. PCR conceived the study, served as the principle investigator, participated in study design, aided in interpretation of results, helped to draft and review the manuscript. All authors read and approved the final manuscript.

\section{Acknowledgements}

This work was supported by NIH Al065591Roberts and NIH AG033825 (High/Roberts). This article fulfills, in part, the PhD thesis requirements for Tila Khan in the Department of Biomedical Sciences and Pathobiology at the VA-Maryland Regional College of Veterinary Medicine at Virginia Tech.

\section{Author details}

1Department of Biomedical Sciences and Pathobiology, 1981 Kraft Drive, Corporate Research Center, Virginia Tech, Blacksburg, Virginia 24061, USA. 
${ }^{2}$ Section on Infectious Diseases, Department of Internal Medicine, Wake Forest University School of Medicine, 100 Medical Center Boulevard, Winston-Salem, NC 27157-1042, USA.

Received: 15 January 2014 Accepted: 23 April 2014

Published: 3 May 2014

\section{References}

1. Furuya Y: Return of inactivated whole-virus vaccine for superior efficacy. Immunol Cell Biol 2011, 90:571-578.

2. Palese P: Making better influenza virus vaccines? Emerg Infect Dis 2006, 12:61-65.

3. Takada A, Matsushita S, Ninomiya A, Kawaoka Y, Kida H: Intranasal immunization with formalin-inactivated virus vaccine induces a broad spectrum of heterosubtypic immunity against influenza A virus infection in mice. Vaccine 2003, 21:3212-3218.

4. Tumpey TM, Renshaw M, Clements JD, Katz JM: Mucosal delivery of inactivated influenza vaccine induces B-cell-dependent heterosubtypic cross-protection against lethal influenza a H5N1 virus infection. J Virol 2001, 75:5141-5150.

5. Stephenson I, Gust I, Pervikov Y, Kieny MP: Development of vaccines against influenza H5. Lancet Infect Dis 2006, 6:458-460.

6. Boyaka PN, Marinaro M, Jackson RJ, Menon S, Kiyono H, Jirillo E, McGhee JR: IL-12 is an effective adjuvant for induction of mucosal immunity. J Immunol 1999, 162:122-128.

7. Babai I, Samira S, Barenholz Y, Zakay-Rones Z, Kedar E: A novel influenza subunit vaccine composed of liposome-encapsulated haemagglutinin/ neuraminidase and IL-2 or GM-CSF. I. Vaccine characterization and efficacy studies in mice. Vaccine 1999, 17:1223-1238.

8. Thompson AL, Staats HF: Cytokines: the future of intranasal vaccine adjuvants. Clin Dev Immunol 2011, 2011:289597.

9. Arulanandam BP, OToole M, Metzger DW: Intranasal interleukin-12 is a powerful adjuvant for protective mucosal immunity. J Infect Dis 1999, 180:940-949.

10. Kodama S, Hirano T, Noda K, Abe N, Suzuki M: A single nasal dose of fms-like tyrosine kinase receptor-3 ligand, but not peritoneal application, enhances nontypeable Haemophilus influenzae-specific long-term mucosal immune responses in the nasopharynx. Vaccine 2010, 28:2510-2516.

11. Barouch DH, Santra S, Tenner-Racz K, Racz P, Kuroda MJ, Schmitz JE, Jackson SS, Lifton MA, Freed DC, Perry HC, Perry HC, Davies ME, Shiver JW, Letvin NL: Potent CD4(+) T cell responses elicited by a bicistronic HIV-1 DNA vaccine expressing gp120 and GM-CSF. J Immunol 2002, 168:562-568.

12. Bungener L, Geeraedts F, Ter Veer W, Medema J, Wilschut J, Huckriede A: Alum boosts TH2-type antibody responses to whole-inactivated virus influenza vaccine in mice but does not confer superior protection. Vaccine 2008, 26:2350-2359.

13. Geeraedts F, Bungener L, Pool J, ter Veer W, Wilschut J, Huckriede A: Whole inactivated virus influenza vaccine is superior to subunit vaccine in inducing immune responses and secretion of proinflammatory cytokines by DCs. Influenza Other Respi Viruses 2008, 2:41-51.

14. Yang YF, Leggat D, Herbert A, Roberts PC, Sundick RS: A Novel Method to Incorporate Bioactive Cytokines as Adjuvants on the Surface of Virus Particles. J Interferon Cytokine Res 2009, 29:9-22.

15. Herbert AS, Heffron L, Sundick R, Roberts PC: Incorporation of membrane-bound, mammalian-derived immunomodulatory proteins into influenza whole virus vaccines boosts immunogenicity and protection against lethal challenge. Virol J 2009, 6:42.

16. Watford WT, Moriguchi M, Morinobu A, O'Shea JJ: The biology of IL-12: coordinating innate and adaptive immune responses. Cytokine Growth Factor Rev 2003, 14:361-368.

17. Trinchieri G: Interleukin-12 and its role in the generation of $\mathrm{TH} 1$ cells. Immunol Today 1993, 14:335-338.

18. Lynch JM, Briles DE, Metzger DW: Increased protection against pneumococcal disease by mucosal administration of conjugate vaccine plus interleukin-12. Infect Immun 2003, 71:4780-4788.

19. Bradney CP, Sempowski GD, Liao HX, Haynes BF, Staats HF: Cytokines as adjuvants for the induction of anti-human immunodeficiency virus peptide immunoglobulin $\mathrm{G}(\mathrm{IgG})$ and $\lg \mathrm{A}$ antibodies in serum and mucosal secretions after nasal immunization. J Virol 2002, 76:517-524.

20. Staats HF, Bradney CP, Gwinn WM, Jackson SS, Sempowski GD, Liao HX, Letvin NL, Haynes BF: Cytokine requirements for induction of systemic and mucosal CTL after nasal immunization. J Immunol 2001 167:5386-5394.

21. Khan T, Heffron CL, High KP, Roberts PC: Tailored Vaccines Targeting the Elderly Using Whole Inactivated Influenza Vaccines Bearing Cytokine Immunomodulators. J Interferon Cytokine Res 2014, 34:129-139.

22. Belladonna ML, Renauld JC, Bianchi R, Vacca C, Fallarino F, Orabona C, Fioretti MC, Grohmann U, Puccetti P: IL-23 and IL-12 have overlapping, but distinct, effects on murine dendritic cells. J Immunol 2002 168:5448-5454.

23. Peng LS, Penichet ML, Dela Cruz JS, Sampogna SL, Morrison SL: Mechanism of antitumor activity of a single-chain interleukin-12 lgG3 antibody fusion protein (msclL-12.her2.lgG3). J Interferon Cytokine Res 2001, 21:709-720.

24. Hagenaars N, Mastrobattista E, Glansbeek H, Heldens J, van den Bosch H, Schijns V, Betbeder D, Vromans H, Jiskoot W: Head-to-head comparison of four nonadjuvanted inactivated cell culture-derived influenza vaccines: effect of composition, spatial organization and immunization route on the immunogenicity in a murine challenge model. Vaccine 2008, 26:6555-6563

25. Muhamed G, Greenbaum E, Zakay-Rones Z: Neuraminidase antibody response to inactivated influenza virus vaccine following intranasal and intramuscular vaccination. Isr Med Assoc J 2006, 8:155-158.

26. Clements ML, Odonnell S, Levine MM, Chanock RM, Murphy BR: Dose-responses of A/Alaska/6/77 (H3N2) cold-adapted reassortant vaccine virus in adult volunteers-role of local antibody in resistance to infection with vaccine virus. Infect Immun 1983, 40:1044-1051.

27. Enioutina EY, Visic D, Daynes RA: The induction of systemic and mucosal immune responses to antigen-adjuvant compositions administered into the skin: alterations in the migratory properties of dendritic cells appears to be important for stimulating mucosal immunity. Vaccine 2000 , 18:2753-2767.

28. Liard C, Munier S, Arias M, Joulin-Giet A, Bonduelle O, Duffy D, Shattock RJ, Verrier B, Combadiere B: Targeting of HIV-p24 particle-based vaccine into differential skin layers induces distinct arms of the immune responses. Vaccine 2011, 29:6379-6391.

29. Belyakov IM, Ahlers JD, Nabel GJ, Moss B, Berzofsky JA: Generation of functionally active HIV-1 specific CD8+ CTL in intestinal mucosa following mucosal, systemic or mixed prime-boost immunization. Virology 2008, 381:106-115.

30. Faulkner L, Buchan G, Slobbe L, Lockhart E, Wales J, Wilson M, Baird M: Influenza hemagglutinin peptides fused to interferon gamma and encapsulated in liposomes protects mice against influenza infection. Vaccine 2003, 21:932-939.

31. Doreau A, Belot A, Bastid J, Riche B, Trescol-Biemont MC, Ranchin B, Fabien N, Cochat P, Pouteil-Noble C, Trolliet P, Durieu I, Tebib J, Kassai B, Ansieau S, Puisieux A, Eliaou JF, Bonnefoy-Bérard N: Interleukin 17 acts in synergy with $B$ cell-activating factor to influence $B$ cell biology and the pathophysiology of systemic lupus erythematosus. Nat Immunol 2009, 10:778-785.

32. Hsu HC, Yang P, Wang J, Wu Q, Myers R, Chen J, Yi J, Guentert T, Tousson A, Stanus AL, Le TV, Lorenz RG, Xu H, Kolls JK, Carter RH, Chaplin DD, Williams RW, Mountz JD: Interleukin 17-producing T helper cells and interleukin 17 orchestrate autoreactive germinal center development in autoimmune BXD2 mice. Nat Immunol 2008, 9:166-175.

33. Jaffar Z, Ferrini ME, Herritt LA, Roberts K: Cutting edge: lung mucosal Th17-mediated responses induce polymeric Ig receptor expression by the airway epithelium and elevate secretory IgA levels. J Immunol 2009, 182:4507-4511.

34. Lo CH, Lee SC, Wu PY, Pan WY, Su J, Cheng CW, Roffler SR, Chiang BL, Lee $\mathrm{CN}$, Wu CW, Tao MH: Antitumor and antimetastatic activity of IL-23. $J$ Immunol 2003, 171:600-607.

35. Oppmann B, Lesley R, Blom B, Timans JC, Xu YM, Hunte B, Vega F, Yu N, Wang J, Singh K, Zonin F, Vaisberg E, Churakova T, Liu M, Gorman D, Wagner J, Zurawski S, Liu Y, Abrams JS, Moore KW, Rennick D, de Waal-Malefyt R, Hannum C, Bazan JF, Kastelein RA: Novel p19 protein engages IL-12p40 to form a cytokine, IL-23, with biological activities similar as well as distinct from IL-12. Immunity 2000, 13:715-725. 
36. Oniki S, Nagai H, Horikawa T, Furukawa J, Belladonna ML, Yoshimoto T, Hara I, Nishigori C: Interleukin-23 and interleukin-27 exert quite different antitumor and vaccine effects on poorly immunogenic melanoma. Cancer Res 2006, 66:6395-6404.

37. Langowski JL, Zhang X, Wu L, Mattson JD, Chen T, Smith K, Basham B, McClanahan T, Kastelein RA, Oft M: IL-23 promotes tumour incidence and growth. Nature 2006, 442:461-465.

doi:10.1186/1743-422X-11-78

Cite this article as: Khan et al: Membrane-bound IL-12 and IL-23 serve

as potent mucosal adjuvants when co-presented on whole inactivated influenza vaccines. Virology Journal 2014 11:78.

\section{Submit your next manuscript to BioMed Central and take full advantage of:}

- Convenient online submission

- Thorough peer review

- No space constraints or color figure charges

- Immediate publication on acceptance

- Inclusion in PubMed, CAS, Scopus and Google Scholar

- Research which is freely available for redistribution 